\title{
Contradições entre a legislação ambiental e a legislação indigenista no Brasil contemporâneo: o protagonismo Mbyá Guarani na autodemarcação da terra indígena Tekoá Mirim
}

Fábio do Espírito Santo Martins ${ }^{1}$

Paulo José Brando Santilli²

\begin{abstract}
ReSumo: Propôs-se neste trabalho evidenciar o protagonismo Mbyá Guarani, concretizado no processo de luta pela autodemarcação da Terra Indígena Tekoá Mirim, cuja localização no interior do Parque Estadual da Serra do Mar, circunscrita pelo município de Praia Grande no litoral do estado de São Paulo, fez com que as instâncias do Poder Executivo Municipal passassem a percebê-los como invasores, e mais, corroborou para que a Secretaria Estadual de Meio Ambiente, assumisse a postura de considerar a permanência dos Mbyá Guarani que vivem na Tekoá Mirim, contraria ao 'corpus legal' que legisla sobre a ocupação humana nas Unidades de Conservação Ambiental. Diante de tal contexto, pretende-se dar visibilidade às motivações sociocosmológicas e etnohistóricas que justificam a dinâmica de deslocamento e ocupação espacial dos Mbyá Guarani nesta autodemarcação territorial.
\end{abstract}

Palavras-chave: Terra indígena; Protagonismo político; Resistência; Democracia.

ABSTRACT: It was proposed in this work to highlight the Mbyá Guarani protagonism, concretized in the process of struggle for the autodemarcation of the Tekoa Mirim Indigenous Land, whose location within the Serra do Mar State Park, circumscribed by the municipality of Praia Grande on the coast of the state of São Paulo, caused that the instances of the Municipal Executive Power happened to perceive them as invaders, and more, corroborated so that the State Secretary of Environment, assumed the posture to consider the permanence of the Mbyá Guarani that live in Tekoá Mirim, contrary to the legal corpus which legislates on the human occupation in the Units of Environmental Conservation. In view of this context, it is intended to give visibility to the sociocosmological and ethnohistorical motivations that justify the displacement dynamics and spatial occupation of the Mbyá Guarani in this territorial self-demarcation.

KEYwORDS: Indigenous Agency; Territorialities; Resistance.

\footnotetext{
${ }^{1}$ Doutorando do PPGCS da UNESP/FCLAr. Membro do CEIMAM (Centro de Estudos Indígenas Miguel A. Menendéz UNESP/FCLAr).E-mail: epiritomartins@bol.com.br

${ }^{2}$ Professor Orientador junto ao Programa de Pós-Graduação em Ciências Sociais na linha de pesquisa Diversidade, Identidades e Direitos.Universidade Estadual Paulista - UNESP/FCLAr. E-mail: santilli@fclar.unesp.br
} 


\section{INTRODUÇÃo}

Quanto à causa indígena no Brasil contemporâneo, as temáticas concernentes à espacialidade e à noção de território vêm sendo alguns dos principais pontos de discussão entre os especialistas nas áreas antropológicas, jurídicas e afins. $\mathrm{O}$ direito fundiário tem remetido à discussão de uma série de conceitos e perspectivas antropológicas e jurídicas, a fim de contemplar as peculiaridades daqueles povos, tanto num plano mais amplo (abordando-os como um todo na categoria de índios), quanto de forma mais específica (quando se trata de cada sociedade indígena). Assim, a articulação Mbyá ${ }^{3}$ com estas questões está diretamente ligada ao

${ }^{3} \mathrm{~A}$ partir de meados do século XX, os estudos etnográficos permitiram maior conhecimento sobre as especificidades linguísticas, religiosas, políticas e sobre a cultura material guarani, definindo as bases para a classificação ainda vigente dos subgrupos. Recentemente, a localização dos grupos e centros de "origem" e "dispersão" são critérios considerados nas classificações e subdivisões desse grupo indígena. Embora esta classificação não corresponda às definições de grupo, origem e situação vivida pelos Guarani, ela não deve ser entendida apenas como um "formalismo classificatório" pois aponta uma definição de diferença explícita e vivenciada pelos próprios índios. O território atualmente ocupado pelos Mbya, Ñandeva (Xiripa) e Kaiowa, grupos Guarani que se encontram hoje no Brasil, compreende partes do Brasil, do Paraguai, da Argentina e do Uruguai. Na região oriental do Paraguai, os Kaiowa e os Nandéva/Xiripa são conhecidos respectivamente por Pai Tavyterã e Ava-Xiripa. Outros grupos Guarani - Guajaki, Tapiete e os conhecidos por Guarayos, Chiriguano também são encontrados no Paraguai e na Bolívia. As aldeias Kaiowa / Pai Tavyterã concentram-se na região oriental do Paraguai e região sul do Mato Grosso do Sul. Algumas famílias kaiowa vivem, atualmente, em aldeias próximas às Mbya no litoral do Espírito Santo e Rio de Janeiro. Diferentemente dos Mbya e Ñandeva que se apresentam como Guarani, os Kaiwa se apresentam como Kaiowa. Os Ñandeva/Xiripa, no Paraguai, concentram-se na região compreendida entre os rios Jejui Guazu, Corrientes e Acaray e, no Brasil, vivem em aldeias situadas no Mato Grosso do Sul, no interior dos estados de São Paulo (Posto Indígena de Araribá), Paraná e Rio Grande do Sul e no litoral dos estados de São Paulo e Santa Catarina. O termo "ñandeva" significa "nós", "todos nós" ou "nossa gente" e é empregado por todos os Guarani. Contudo, é a única forma de apresentação daqueles que falam o dialeto que o etnógrafo Kurt Nimuendaju levantou com o nome de Apapukuva ou pelos descendentes dos grupos Tanigua, Apapukuva e Oguauiva). No Mato Grosso do Sul, os Ñandeva são conhecidos como Guarani, distinguindo-se dos Kaiowa, e no Paraguai como Ava-Chiripa, em referência à sua vestimenta tradicional. Os Mbya estão presentes em várias aldeias na região oriental do Paraguai, no nordeste da Argentina (província de Misiones) e no do Uruguai (nas proximidades de Montevideo). No Brasil encontram-se em aldeias situadas no interior e no litoral dos estados do sul - Paraná, Santa Catarina, Rio Grande do Sul - e em São Paulo, Rio de Janeiro e Espírito Santo em várias aldeias junto à Mata Atlântica. Também na região norte do país encontram-se famílias Mbya originárias de um mesmo grande grupo e que vieram ao Brasil após a Guerra do Paraguai. No litoral brasileiro suas comunidades são compostas por grupos familiares que, historicamente, procuram formar suas aldeias nas regiões montanhosas da Mata Atlântica - Serra do Mar, da Bocaina, do Tabuleiro. O nome mbya foi traduzido por "gente". A população Guarani no litoral é salva exceções, composta pelos Mbya e Ñandeva. Segundo alguns registros (documentos do arquivo do Estado), até as primeiras décadas do século XX, os Ñandeva constituíam a maioria da população Guarani no litoral de São Paulo. Levantamentos realizados a partir das décadas de 1960 e 1970, e a crescente visibilidade das aldeias, na atualidade, comprovam que os Mbya passaram a predominar numericamente, em toda a faixa litorânea do Rio Grande do Sul ao Espírito Santo. Vale realçar que algumas aldeias apresentam contingente populacional composto por descendentes de casamentos mistos entre Ñandeva e Mbya (assim como no Mato Grosso do Sul, entre os Ñandeva e Kaiowa). A organização social e as atividades desempenhadas em cada comunidade dependerão sobretudo da orientação religiosa que absorve os modos, representações e experiências, de origens ou de subgrupos diversos, criando um perfil próprio. Em aldeias onde há indivíduos de outro subgrupo, estes passam a respeitar as regras (sociais, políticas) e a adotar costumes e rituais do grupo local dominante. Mesmo se tratando de uma aldeia composta por famílias do mesmo subgrupo, nem sempre há uma autodenominação geral e consensual. Perante as instituições da sociedade nacional, identificam-se como Guarani (Ñandeva e Mbya) e Kaiowa. São os Mbya, dentre os grupos Guarani, que vêm ocupando com continuidade áreas no litoral Atlântico. Além do motivo comum - a busca da terra sem mal (yvy marãey), da terra perfeita (yvyju miri), o paraíso aonde para se chegar é preciso atravessar a 'grande água' -, o modo como os grupos familiares traçam sua história através das caminhadas, recriando e recuperando sua tradição num 'novo' lugar, faz com que sejam portadores de uma experiência de vida e de sobrevivência também comuns. Assim como 
acentuado interesse das populações Guarani, em concretizar seu direito de posse territorial, especialmente a partir da Constituição Federal de 1988 (CF 1988), em particular, no Art. 231 e 232. Portanto, ao relacionar-se os Mbyá Guarani com esse tema, observa-se a necessidade de uma análise que priorize tanto os aspectos teóricos que envolvem o peculiar conceito de território deste povo, quanto a história de contato dessa população com a sociedade envolvente. Enfocar ambos os elementos, é imprescindível, pois, que os problemas relacionados à saúde, organização social e demografia estão imbricados e subsumidos na questão fundiária.

Desta forma, pretendeu-se analisar neste trabalho, a partir das concepções nativas dos Mbyá Guarani que vivem na Terra Indígena (TI) Tekoá Mirim, as suas relações com o espaço e com a sociedade evolvente, além de como elas forjaram mudanças históricas que influenciaram a sua configuração sociocultural contemporânea. Mas, sobretudo, como esses aspectos convergem para uma compreensão acerca da sua agência e protagonismo na questão fundiária que os afeta.

Neste sentido, é preciso inicialmente, evidenciar a perspectiva de espacialidade concebida pelos Guarani. Devendo então, ser considerado que eles, ao se fixar em uma área específica, tradicionalmente se estabelecem sem a preocupação de definir limites precisos. Entretanto, o processo histórico de constante contato com a sociedade envolvente impôs mudanças nesse aspecto. Desta maneira, pretende-se evidenciar a luta dos Mbyá no contexto de autodemarcação da TI Tekoá Mirim, no município de Praia Grande no litoral do estado de São Paulo. TI esta, exatamente localizada no interior da Unidade de Conservação (UC) ambiental do Parque Estadual da Serra do Mar (PESM). Contexto, que fez com que as instâncias do Poder Executivo Municipal passassem a considerar os Mbyá que lá se instalaram, como invasores; e mais, situação que corroborou para que os órgãos ambientais estaduais, sobretudo, a Secretaria Estadual de Meio Ambiente de São Paulo (SEMA - SP) responsável administrativo do PESM, assumisse a postura de considerar a permanência indígena na Tekoá Mirim contrária ao “corpus” legal que legisla sobre a ocupação humana nas UC ambientais, dando início portanto, a uma articulação político-administrativa para impossibilitar a sua permanência naquele território. Permanência esta, que remonta a uma posse que secularmente está assegurada pela concretização sócioespacial do modo de vida próprio dos Mbyá,

o sistema de reciprocidade e as vivências comuns são aspectos integradores dos Mbya, os fatores atuais de diferenciação destes com os outros subgrupos guarani residem nas divisões espaciais, em expressões linguísticas, em elementos da cultura material (adornos, artefatos de uso ritual) e nos rituais nos quais há músicas e cantos específicos. (BRASIL/INSTITUTO SOCIOAMBIENTAL, 2019). 
Mapa 1 - Terras Indígenas na Baixada Santista. Tekoá Mirim, TI localizada no município de Praia Grande, e ainda não demarcada.

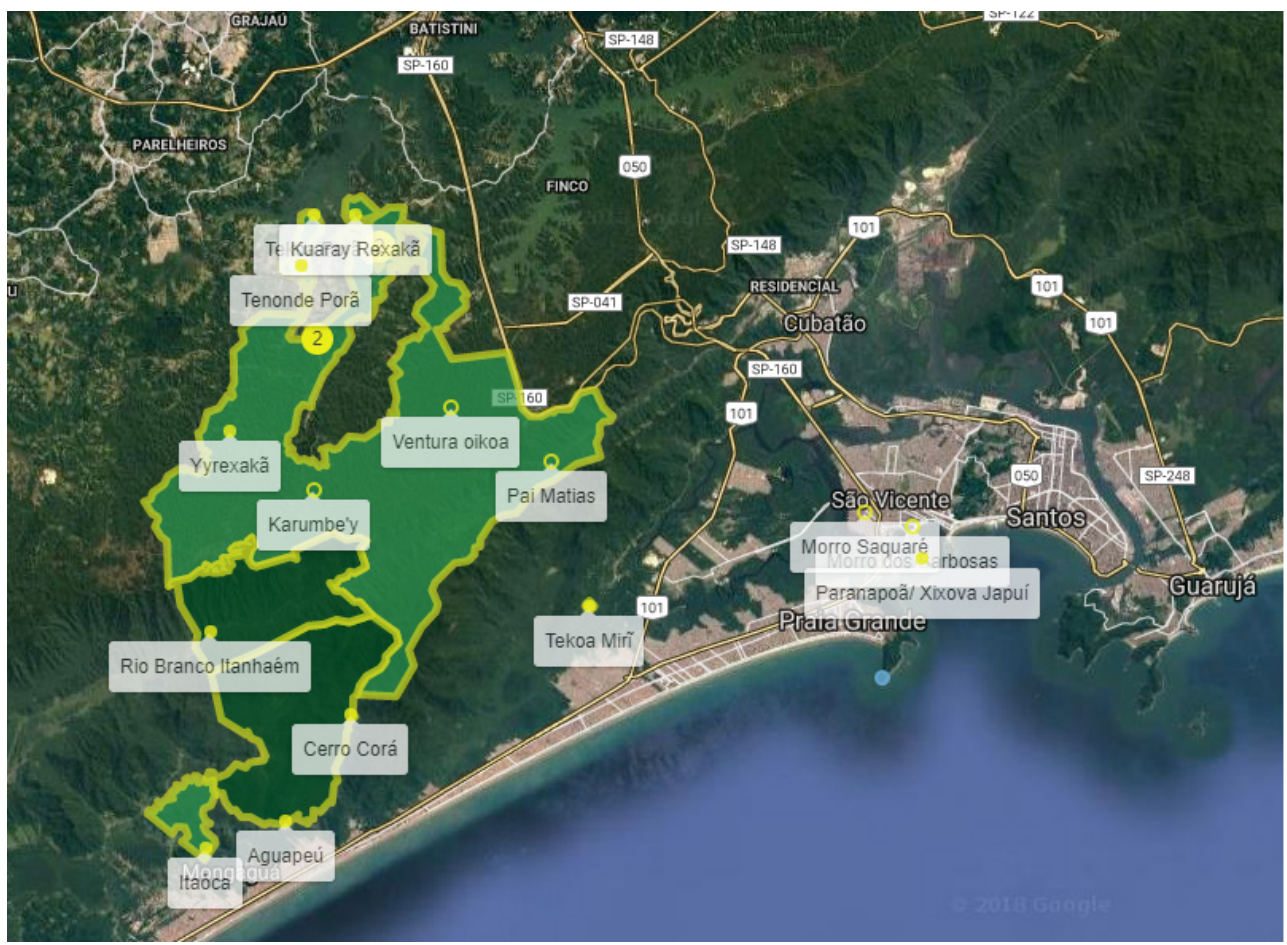

Fonte: Mapa Guarani Digital.

culturalmente peculiar, ou seja, o seu Nhanderekó ${ }^{4}$, completamente ignorado e desprezado pelas representatividades do Estado brasileiro.

Assim, diante de tal contexto, pretendeu-se dar visibilidade às motivações sociocosmológicas, culturais, portanto, que justificam a dinâmica de ocupação espacial dos Mbyá. Problematizando também, os processos etnohistóricos que justificam a sua autenticidade. Por isso, as reflexões contidas nesta discussão, irão se referir às análises executadas sobre o fato de que os Mbyá Guarani ao estabelecerem a Tekoá Mirim, o fizeram em execução plena de concretização e consonância de sua cosmologia com a sua práxis dialógica derivada das relações estabelecidas com a sociedade envolvente. O que possibilitou verificar a atuação do Estado diante desta situação, e assim, constatar que a legislação que a norteia,

\footnotetext{
${ }^{4}$ Nhanderekó é como nós, Guarani M'bya, chamamos o que o juruá (não índio) chama de cultura. Mas Nhanderekó para nós é mais do que isso. É todo o nosso modo de ser, o nosso modo de viver, o jeito como nós educamos nossos filhos e nossas filhas, como enxergamos o mundo, como nos relacionamos com a nossa espiritualidade. É impossível para o juruá entender o que é o Nhanderekó, porque somente vivendo é que se compreende o que ele é” (COMISSÃO GUARANI YVYRUPA).
} 
padece de uma profunda e ininteligível contradição, sobretudo, quando se relaciona diretamente à garantia dos direitos dos povos indígenas. E, de maneira mais específica, quando define as questões relacionadas às TIs e a posse das mesmas pelos respectivos povos que secularmente as utilizam.

Sendo assim, fica evidenciado que no decorrer dos séculos, as relações de contato pouco mudaram, frutos da recusa em se admitir que povos com outras visões de mundo, de espaço e de tempo e com outros costumes e tradições possam coexistir em espaços compreendidos e classificados de maneiras diferentes em relação àquelas padronizadas pela sociedade envolvente ou hegemônica.

\section{O Nhanderekó COMO CONDição DETERMinANTE PARA A CONCRETIZAÇÃo} DA TEKOÁ MIRIM

O cotidiano vivenciado pelos Mbyá Guarani da TI Tekoá Mirim passa a ser apresentado e problematizado em relação àquilo que se refere às dificuldades enfrentadas por eles para poderem estabelecer-se e se manter de acordo com o seu modo tradicional de existência cultural, ou seja, o seu Nhanderekó o que, influenciado por sua cosmologia, se materializa na ocupação e utilização do espaço social. Assim, é a partir da análise deste material que se problematizará o processo de fixação do mencionado grupo indígena na Tekoá Mirim. Portanto, discutir-se-ão as complexas composições culturais Mbyá que atestam, tratar-se como seu território ancestral, a área escolhida para se fixarem e concretizarem a sua Tekoá. Desta forma, invalidando a compreensão e posteriores ações de várias esferas do poder público municipal e estadual, que passaram a considera-los como invasores do seu próprio território. Situação, pretensamente avalizada, segundo o Estado, pelo fato de que a TI em questão, se localiza circunscrita pelas delimitações espaciais do PESM, classificado de acordo com a legislação ambiental como uma UC, o que por definição, exclui completamente dos povos indígenas os seus direitos originais de permanecerem a habitá-las. Desconsiderando-se, portanto, o fato de que aquelas terras são ocupadas por eles desde remotos períodos, quando história e mito se permeavam na elaboração de uma realidade particular.

Neste sentido, a proposição deste trabalho compõe-se justamente, a partir do inédito acompanhamento antropológico nesta TI, simultaneamente, ao processo de fixação do grupo indígena em questão. Priorizando assim, a apreensão etnográfica das relações sociais, políticas, econômicas, rituais e religiosas estabelecidas. Além, é claro, daquelas que são mantidas com elementos pontuais da sociedade envolvente.

Então, a análise desenvolvida deriva principalmente, da interlocução junto aos Mbyá, sendo inestimáveis as contribuições que o Xeramo 'i Karaí Mirim, tanto

\footnotetext{
${ }^{5}$ Liderança espiritual, religiosa e de grande influência política na cultura Mbyá Guarani, detendo além destas categorias, os saberes mitológicos, históricos e da memória deste povo.
} 
quanto o cacique Karaí Ñee're disponibilizaram incondicionalmente.

Sendo cabível, portanto, a clara percepção que o local exato em que se dera a concretização desta aldeia, em hipótese nenhuma, se materializou motivado por circunstâncias aleatórias. Ao contrário, concretizou-se a partir das complexas premissas culturais que influenciaram a lúcida e consciente opção. Evidenciando, que sob a óptica Mbyá Guarani, toda a espacialidade geográfica que abriga a Serra do Mar, e, por consequência, que circunscreve a área escolhida como aquela a conter a Tekoá Mirim, trata-se de território indígena (Mbyá) ancestral. Já, que os Guarani se movimentam numa ampla geografia, com migrações eventuais a regiões bastante específicas.

Destarte, como afirma LADEIRA (2007, p.87), “A noção de terra está, pois, inserida no conceito mais amplo de território que sabidamente pelos Mbyá se insere num contexto histórico (mítico) cíclico, e, portanto, permanentemente recriado e ressignificado, pois ele é o próprio mundo Mbyá”.

O tekoá é traduzido como o lugar onde é possível realizar o modo de ser Guarani. Tekó, "o modo de ser", abrange a cultura, as normas, o comportamento, os costumes. O tekoá com toda a sua materialidade terrena, é, sobretudo uma interrelação de espaços culturais, econômicos, sociais, religiosas e políticos. Na verdade, "fundar" um tekoá, ou recuperá-lo ou reconstruí-lo mediante as unidades familiares, é realizar o projeto coletivo de reconstrução do mundo Mbyá por meio da reprodução, nos diversos tekoá, dos elementos originais existentes em yvy apy (LADEIRA, 2007, p.93-94).

Então, a predileção dos Mbyá por fixar-se no território compreendido pela Serra do Mar se justifica por aspectos culturais que tangenciam o plano das concepções mitológicas, principalmente, encontrando fundamento no mito "da origem da terra sem males (yvÿ pyaú)”, como foi registrado por CLASTRES (1978). Assim como também, fatores de ordem práticas relativa a práxis destes indígenas em relação à espacialidade que ocupam, corroboram por justificar a sua preferência pelas regiões serranas do litoral. Por isso, "quando os Mbyá definem a Serra do Mar como "terra boa” (tekoá porã), isso significa que ali ainda é possível reproduzir as normas tradicionais em termos do uso da terra e da relação com os parentes" (AZANHA; LADEIRA, 1988, p.24). O que essas informações significam? De acordo com as afirmações de Azanha e Ladeira (1988): "Isso quer dizer que a escolha do lugar não é gratuita: ela segue a tradição, seja ela histórica e/ou cosmológica". Portanto, graças a sua experiência religiosa e a seu sistema de vida, os Guarani vêm resistindo e mantendo o seu existir circunscrito às Tekoá, o lugar do seu modo de ser. Assim, 
a possibilidade de prática do Nhanderekó, é a concretização de se reproduzir a manutenção da terra em seu próprio suporte.

Por isso, insistir na perspectiva conservacionista radical, significa associar-se a permissividade da exclusão do direito Mbyá Guarani de permanecer habitando sua espacialidade territorial cosmologicamente constituída. E mais, desse modo, mantendo essas práticas autoritárias, em benefício das populações urbanizadas o Estado contribui para a perda de enormes potencialidades de etnoconhecimentos e etnociência, de sistemas criativos de manejo de recursos naturais e da própria diversidade cultural.

Devendo então, ficar bastante claro como a concepção sociocosmológica, portanto, culturalmente ancestral, preconizou tanto a seleção e fixação territorial, quanto à contextualização das dinâmicas de estabelecimento da Tekoá Mirim. Desta maneira, com relação às prerrogativas socioculturais Mbyá que concretizaram suas significações e subjetividades cosmológicas através de motivações práticas para a constituição de sua "nova" Tekoá, um importante exemplo, manifestado pelo grupo indígena em questão, e etnografado no trabalho de campo, se refere à memória sobre o uso ritual que os ancestrais dos Mbyá contemporâneos executavam na territorialidade que atualmente circunscreve a área de instalação da Tekoá Mirim. Memórias estas, que evidenciam algumas das considerações que compõem o entendimento Mbyá a respeito da posse mítica (histórica) de seu território, que, somada ao ordenamento jurídico ocidental que reconhece o "direito originário" dos povos indígenas sobre os seus territórios, por si só, deveriam se caracterizar como a justificativa legal para a inquestionável fixação e utilização culturalmente peculiares, que os Mbyá reivindicam para a sua Tekoá Mirim.

\section{Algumas incoerênCias E CONTRADIÇões ENTRE AS LEGISLAÇÕeS AMBIENTAL} E INDIGENISTA NO BRASIL CONTEMPORÂNEO

A atualidade que caracteriza e concretiza as mitigações para apropriação, gestão e utilização dos recursos naturais das áreas Mbyá situadas no litoral de São Paulo, impõe uma definição cada vez mais precisa de papéis, direitos e competências, dadas as transformações sucessivas dessa região, provocadas pela sua ocupação crescente e desordenada. Haja vista, os claros e permanentes impactos que incidem de modo incessante sobre as comunidades Mbyá que tradicionalmente habitam a territorialidade supracitada. Sendo estas consequências, relativas à articulação de aplicabilidade entre as legislações ambiental e indigenista sobre o cotidiano e práxis destas comunidades.

Assim, a Lei Federal nº 9.985/00, responsável por reformular a gestão e 
usos das áreas ambientalmente protegidas, denominadas desde então como UC ambientais, ignora de maneira total as populações tradicionais, entre elas, os povos indígenas, que habitam ancestralmente estas áreas. Desta forma, sob a égide do conservacionismo ecológico, que desconsidera as interações e os processos de interferência das populações humanas sobre o meio natural em que se encontram inseridos há séculos, exclui de modo enfático, os Mbyá de permanecerem ocupando seus territórios.

Mas, para uma análise mais aprofundada deste contexto, convém evidenciar que a incumbência de garantir os direitos indígenas, inclusive os territoriais, deriva da CF de 1988, em seu art. 231, cap. VIII, $\S 1^{\circ}$, regulamentados pelo Decreto $\mathrm{n}^{\mathrm{o}} 1.775$ e pela Portaria nº14 de 1996. Devendo também ser destacado, que, em 2003, ao ratificar a Convenção 169 sobre Povos Indígenas e Tribais em Países Independentes (C169) da Organização Internacional do Trabalho (OIT), o Brasil comprometeuse juridicamente, perante a comunidade internacional a proteger a identidade dos povos indígenas, respeitando suas terras, tradições e formas próprias de organização social. Já que, “A C169 estabeleceu normas específicas para a proteção das terras indígenas e tribais” (FIGUEROA, 2009, p.20).

Deste modo, diante do contexto de conflito existente na Tekoá Mirim, as reivindicações Mbyá quanto à legitimidade da sua ocupação e usos próprios, amparam-se, sobretudo, no Art.14, $\S \S 1^{\circ}, 2^{\circ}$ e $3^{\circ}$ daquela Convenção. Situação esta, que é corroborada pelo Decreto $n^{\circ} 6.040 / 07$, que instituiu a Política Nacional de Desenvolvimento Sustentável dos Povos e Comunidades Tradicionais.

Portanto, de que maneira compreender este antagonismo que coloca em oposição direta estas legislações? Situação constatada nos exemplos que "em muitos casos, se têm acarretado a expulsão dos moradores tradicionais de seus territórios ancestrais, como exige a legislação referente às unidades de conservação" (DIEGUES, 2000, p. 11). Contexto este, em que estão incluídos os Mbyá da Tekoá Mirim.

Desta forma, concretiza-se uma contradição legal que opõe a legislação que determina sobre a gestão das UC ambientais, e a CF de 1988, que, por sua vez, legisla a respeito da prevalência dos direitos territoriais indígenas, inclusive dos que tradicionalmente ocupam as territorialidades das UC. Destarte, tal dissonância se caracteriza por um processo alienado e alienante de importação/composição da legislação ambiental, que regulamenta a gestão das UC no país. E que reproduziu, quase que literalmente, a concepção de áreas protegidas que provém do século retrasado, criadas nos EUA. Que, segundo DIEGUES (2000, p.13) "mais do que a criação de um espaço físico, existe uma concepção específica de relação homem/ natureza" que compreende o ser humano, inevitavelmente, como destruidor. Assim, pressupõe que poderiam existir pedaços do mundo natural em seu estado primitivo, 
anterior à intervenção humana. Pois, sob a argumentação preservacionista, se posicionam justificativas contra a existência das populações tradicionais em áreas naturais protegidas, já que consideram incompatível a presença destas populações e a proteção da biodiversidade naquelas áreas. O que atesta o desconhecimento de estudos recentes que afirmam que a manutenção, e mesmo o aumento da diversidade biológica nas florestas tropicais, está relacionada intimamente com as práticas tradicionais da agricultura itinerante dos povos indígenas. Apontando desta forma, para a desmistificação das "florestas intocadas" e para a importância das populações indígenas e tradicionais na conservação da biodiversidade, já que, "a natureza em estado puro não existe, e as regiões naturais usualmente correspondem a áreas extensivamente manipuladas pelos homens" (DIEGUES, 2000, p.13).

Contudo, no Brasil, no plano da administração federal e de algumas ONGs, a questão da presença de povos indígenas, e demais populações tradicionais em UC tem sido pensada e articulada a partir de uma visão conservadora e reacionária, influenciada por percepções urbanas do que significa o "mundo natural" e a "natureza selvagem". Fala-se em interferência humana negativa sobre as áreas naturais protegidas sem nenhuma distinção entre os interesses econômicos que prevalecem no contexto externo dessas áreas e as atividades daquelas populações em grande parte responsáveis pela manutenção da diversidade biológica.

\section{Alguns processos de Construção para novas possibilidades na TEKó⿱ MIRIM}

Quanto às aproximações e os distanciamentos políticos estabelecidos entre a Tekoá Mirim e as demais aldeias Mbyá que se encontram ao seu redor, percebe-se que a partir das constantes e mútuas visitas entre os habitantes das aldeias vizinhas e vice-versa, mantêm-se uma identidade política comum. Sobretudo, quando se veem frente a problemas que compreendem a oposição da sociedade envolvente em relação a qualquer uma das aldeias Guarani no litoral sul paulista. Imediatamente, todas elas assumem uma posição de união e unicidade quanto à postura de defesa do posicionamento indígena. Reafirmando assim, a identidade comum a todos eles, de serem Guarani, indígenas, portanto, que lutam pelo reconhecimento e acessibilidade à especificidade dos seus direitos, legalmente reconhecidos pela CF de 1988.

Entretanto, ao que se refere ao relacionamento entre as aldeias do litoral sul de São Paulo, principalmente, aquelas localizadas em São Vicente, Mongaguá, Itanhaém e Pariquera-açú, a construção da Opy'i, a Casa de Rezas da Tekoá Mirim, tal qual se concretizara, passou a assumir um caráter de elemento cultural comunicador, que expressa o entendimento próprio que os Mbyá da Tekoá Mirim assumem sobre si em relação aos seus parentes das demais aldeias que se localizam em regiões 
circunvizinhas. Ou seja, segundo os registros etnográficos que foram coletados em interlocução com o Xeramo 'i Karaí Mirim, que era naquele momento o detentor dos conhecimentos relativos às técnicas e aos procedimentos de construção da nova Opy'i, a configuração que ela passaria a assumir, mediante aos procedimentos e técnicas a serem utilizados na sua confecção, expressariam a maneira com que os "verdadeiros" Mbyá realizavam tal processo de construção. Assim, estando nas entrelinhas, a afirmação sobre os Mbyá da Tekoá Mirim, que seriam eles, étnica e culturalmente falando, os "verdadeiros" Mbyá, em oposição aos outros Guarani das demais aldeias ${ }^{6}$. E mais ainda, já que além da criação de um contexto de distinção étnico cultural, os procedimentos e técnicas de construção da sua nova Opy'i, ao estar concluída, expressaria também a opção e as preferências para a concretização das articulações políticas a se materializarem entre eles e outras Tekoá Mbyá, que não aquelas que os circunscrevem no litoral sul paulista. Tratava-se, portanto, das aldeias Mbyá localizadas ao norte da Argentina, local de nascimento do Xeramo 'i Karaí Mirim e onde ainda hoje mantém estreito relacionamento com os seus parentes que lá vivem, seja pelo fato de que algumas de suas filhas encontram-se casadas naquela localidade, ou pela situação de que regularmente o Xeramo 'i o visita com a sua família; mas principalmente, devido a ter se concretizado um deslocamento do Xeramo 'i à região mencionada, não para uma visita regular, mas sim, para que fosse trazido por ele até a Tekoá Mirim, um de seus genros (Martim), que segundo o xamã, apesar de ele deter os conhecimentos necessários à construção, apenas Martim é que saberia executá-los. Assim, como há muito já consta na literatura antropológica, e havia sido destacado por Lévi-Strauss, pode-se notar no contexto acima indicado, a existência de um fluxo de trocas, de conhecimentos (bens subjetivos) e indivíduos, para o estabelecimento de alianças. A estruturação de um processo consciente de articulação seletiva para o estabelecimento de determinados conjuntos de relações políticas, em detrimento de outras.

Já, quanto à conclusão dos trabalhos de construção da Casa de Rezas, para além das significações cosmológicas e culturais que ela expressa, significa também, a materialização de um complexo conjunto de conhecimentos ecológicos e de uso e manejo sustentável do ambiente que os Mbyá ocupam, atribuem significações e o utilizam de maneira integral, concebendo-se a si mesmos como parte constituinte, e não como elementos externos a este mesmo complexo sistema ambiental.

\footnotetext{
${ }^{6} \mathrm{Tal}$ contexto, explicitado pela análise etnográfica que o registrou e complementado pelas discussões teóricas propostas por autores como Oliveira Filho (1995) e (1998), Souza (2000) e Carneiro da Cunha (2014), diz respeito a agência que os Mbyá Guarani concebem e manipulam sobre a sua condição identitária. Assim, de modo consciente, os indígenas articulam sua identidade entre as seguintes polaridades: "índios" ou "Mbyás". Decisão está, que será determinada por uma específica situação política, ou seja, relações circunscritas pelo contato com os demais grupos indígenas ou com setores diversos da sociedade envolvente hegemônica.
} 
Deste modo, portanto, alguns registros referentes ao processo de construção da nova Opy'i levado a cabo pelos Mbyá na Tekoá Mirim, podem contribuir perfeitamente para que ele seja compreendido como uma clara analogia a outros importantes processos de construção que a referida população indígena está desenvolvendo em seu contexto cotidiano de relações com a sociedade envolvente na contemporaneidade. Mas, sobretudo, com o Estado, seja nas suas esferas municipais, estadual e federal.

Assim, a reflexão a seguir, que deriva da etnografia concretizada ao longo do trabalho de campo, virá exemplificar alguns daqueles processos. Como a articulação das lideranças da aldeia junto à Câmara Municipal de Praia Grande, para que através destes contatos, passasse a estar ampliado o potencial de pressão que os representantes da Tekó Mirim, viessem a executar sobre o Poder Executivo Municipal. Por exemplo, sobre a Secretaria Municipal de Saúde, no sentido que os seus direitos constitucionais que garantem o pleno atendimento dos serviços municipais de saúde a todos os cidadãos, fossem efetivamente garantidos quanto à sua acessibilidade.

Portanto, frente à ineficiência do Estado, os Mbyá da Tekoá Mirim se mobilizam, assumindo-se enquanto portadores de agência, e, desta forma, construtores do protagonismo diante da necessidade de enfrentarem situações de mitigação junto aos órgãos representativos do Estado, sobretudo, quando a inoperância deste, passa a comprometer diretamente as suas condições de vida.

Outro processo de luta que vem sendo construído pelos Mbyá da Tekoá Mirim se caracteriza pela ação das lideranças da aldeia, principalmente do cacique e dos professores, diz respeito à pressão que estes vêm exercendo sobre uma esfera estadual de representação do Estado, a saber, a Diretoria de Educação de São Vicente, representante direta da Secretaria Estadual de Educação, sobre os assuntos relativos às escolas e a educação indígena. É justamente em oposição a precariedade que se dirige a ação das lideranças Mbyá, que em perfeita consonância com o contexto contemporâneo de luta dos povos indígenas pela valorização de seus conhecimentos, saberes e processos educacionais próprios, elaboram a construção de projetos e propostas pedagógicas e curriculares propriamente ditas, que não apenas valorizem, mas que sejam pautados pelo "sistema pedagógico" peculiar a cultura Mbyá.

Entretanto, nenhum processo de luta que está contemporaneamente, sendo construído pelos Mbyá da Tekoá Mirim, é mais difícil do que aquele que se refere ao enfrentamento à morosidade característica aos processos legais de reconhecimento, homologação e demarcação da TI Tekoá Mirim. Dificuldade esta, que se concretiza, sobretudo, pelo fato de que o objetivo final desta luta, ou seja, a demarcação legal 
submete os Mbyá que lá vivem, a "fronts" múltiplos e simultâneos de construção desta luta.

Desta forma, os Mbyá da Tekoá Mirim veem-se frente à necessidade de construírem estratégias de luta para poderem concretizar o enfrentamento, para além dos preconceitos históricos que a sociedade envolvente mantém em relação aos povos indígenas, principalmente quando se trata da relação estabelecida entre estas populações e a posse de suas terras. Haja vista, especificamente, ao que se refere aos Mbyá da Tekoá Mirim, as dificuldades criadas e impostas pelo Poder Executivo Municipal de Praia Grande, tanto quanto, pelo Poder Executivo Estadual, na sua ação através da SEMA-SP, cuja atuação junto a esta comunidade indígena, imediatamente após a sua fixação na área correspondente a Tekoá Mirim, dirigiuse sempre em sentido de dificultar, e mesmo de impedir o seu estabelecimento naquele território.

Entretanto, há ainda maiores e piores dificuldades de enfrentamento a serem superadas pelos Mbyá da TI Tekoá Mirim naquilo que se refere ao processo de construção de sua luta pela demarcação fundiária de seu território tradicional. E, que na contemporaneidade, diz respeito à elaboração da estrutura institucional do país, haja vista, portanto, todos os processos legais relacionados à demarcação das TIs em território nacional estarem completamente paralisados. Situação esta, que se deve as discussões institucionais, que envolvem diretamente o Poder Executivo e o Poder Legislativo federais, e indiretamente, os nefastos e, economicamente falando, vultosos interesses dos lobistas que atuam em consonância com específicos representantes daqueles poderes, que, por sua vez, pretendem alterar todo o contexto institucional, jurídico e legal, àquilo que se refere às demarcações das terras indígenas, isto por meio do Projeto de Emenda Constitucional $n^{\circ} 215$, ou simplesmente, a PEC 215. Que de maneira sumária, pretende anular as atribuições atuais do Poder Executivo Federal, que por meio das atuações da FUNAI e do Ministério da Justiça, são os responsáveis pela execução de todas as etapas relativas aos processos de reconhecimento, homologação e, por conseguinte, de demarcação das terras indígenas no país, para então transferi-las, em sua integridade, direta e unicamente, para o Poder Legislativo Federal, isto é, para o Congresso Nacional.

Contudo, para uma real e crítica percepção deste contexto, é necessário que seja considerada a composição histórica da bancada de maior influência daquela casa, e, que na maioria das vezes, define a direção a qual são encaminhadas a maior parte das discussões que opõe diretamente, os seus interesses aos de outros grupos da sociedade, sobretudo, quando se trata de grupos marginalizados. Neste sentido, observamos no contexto político e social contemporâneo no Brasil, o Congresso 
Nacional, composto de uma maneira fragmentada ao extremo, politicamente falando, além de definir-se a partir de um caráter essencialmente conservador, com a clara predominância dos interesses econômicos e, portanto, políticos, da bancada ruralista, representante do agronegócio, que assume claro, interesses e prioridades diametralmente opostas àquelas manifestadas pelos povos indígenas, principalmente, quando tais interesses se referem à propriedade e usos de terras em território nacional.

Assim, de maneira geral, a luta dos povos indígenas no Brasil, pelo reconhecimento e demarcação legal de seus territórios tradicionais, e especificamente, de modo semelhante, a construção da luta dos Mbyá da Tekoá Mirim, passam a se caracterizar na contemporaneidade, como um complexo processo, cujas dificuldades se multiplicam quando se passa a considerar o cenário político institucional do país na atualidade, o que imediatamente, causa a necessidade de que múltiplos setores da sociedade civil organizada passem a reconhecer verdadeiramente, o contexto que circunscreve as problemáticas relacionadas às questões das demarcações das Terras Indígenas. É, portanto, nesta perspectiva, que este trabalho propõe se constituir como uma colaboração, ao apresentar, a partir de evidências etnográficas e antropológicas ${ }^{7}$ a ancestral relação sociocultural e cosmológica, que une o grupo indígena Mbyá aqui pesquisado com o referido território da Tekoá Mirim.

\section{Considerações Finais}

Conclusivamente, a realização deste trabalho pretendeu caracterizá-lo como um elemento auxiliar às demandas dos povos indígenas e demais interessados, por instrumentos teóricos e metodológicos que ajudem a efetivar ações concretas em contextos que circunscrevem os processos de luta pela demarcação das TIs no país. Para tanto, tratou-se aqui de maneira específica, das condições que caracterizam a realidade contemporânea do grupo indígena Mbyá Guarani no processo de ocupação territorial e constituição da sua Tekoá Mirim.

Neste sentido, as principais contribuições deste trabalho estão circunscritas ao contexto de que, inicialmente, esta é a primeira investigação etnográfica realizada junto aos Mbyá da Tekoá Mirim, portanto, o ineditismo destas análises poderiam explicar suas possíveis limitações, porém, é este mesmo ineditismo que garante os primeiros registros acerca de todo o complexo processo de ocupação territorial que realizaram; do estabelecimento de sua nova Tekoá e dos usos que efetuam sobre o ambiente ocupado. Situação esta, que pode vir a colaborar em grande medida com os novos trabalhos a serem desenvolvidos junto a esta população.

${ }^{7}$ Detalhes metodológicos relacionados ao desenvolvimento desta pesquisa podem ser acessados em Martins (2015). 
Outra contribuição específica deste trabalho se caracteriza pelo fato de que, fica revelado o constante e ininterrupto processo de manutenção e reprodução sociocultural dos Mbyá Guarani do litoral sul de São Paulo, sobretudo da baixada santista, àquilo que se refere a sua mobilidade espaço-territorial, processo este que garante a reprodução de sua forma própria de viver, e que, portanto, contrapõe-se a predominância do senso comum, que insiste na manutenção da errônea concepção de que a referida região, já não é mais habitada por povos indígenas na atualidade.

Assim, pode-se considerar que algumas das contribuições que este trabalho pretende concretizar, referem-se a articulação entre as complexas realidades étnicas, cosmológicas, legislativas, de interesses políticos e econômicos efetuadas entre os Mbyá da Tekoá Mirim e a sociedade envolvente, o que, por sua vez, possibilitou alguns apontamentos sobre o contexto de luta dos Mbyá. Apontamentos estes, que pretendem auxiliá-los a garantir o reconhecimento legal sobre a ocupação que realizaram em seu território ancestral.

Para tanto, se faz extremamente necessário em relação às análises e considerações aqui propostas, que seja evidenciada a inércia quanto às concepções e aplicação dos direitos fundiários dos povos indígenas no país. Principalmente, quando se sobrepõem a territórios ancestrais, cultural e cosmologicamente já definidos quanto à posse e utilização, leis alienígenas a estas culturas, que de modo ignorante, egoísta e violento lhes são outorgadas pela sociedade ocidental pretensamente civilizada. Pois, sob a argumentação preservacionista, se posicionam justificativas contra a existência das populações tradicionais em áreas naturais protegidas, já que consideram incompatíveis a presença e manutenção destas populações com a proteção da biodiversidade naquelas áreas. O que atesta o desconhecimento de estudos recentes que afirmam que a manutenção, e mesmo o aumento, da diversidade biológica nas florestas tropicais, está relacionada intimamente, com as práticas tradicionais da agricultura itinerante dos povos indígenas. Apontando desta forma, como indicara Diegues (2000), à desmistificação das "florestas intocadas" e à importância das populações indígenas e tradicionais na conservação da biodiversidade.

Enfim, considera-se conclusivamente, que mesmo sob a afirmativa da necessidade da reparação histórica e jurídica aos povos indígenas, quanto ao reconhecimento territorial e acesso aos seus direitos de posse e usos tradicionais permanentes, estes procedimentos devem se submeter as concepções e usos tradicionais, previamente estabelecidos por cosmologias peculiares a cada uma das populações indígenas reparadas pelas políticas fundiárias do Estado.

Já, quanto aos Mbya da Tekoá Mirim, apesar das dificuldades decorrentes da 
luta pelo reconhecimento e demarcação de sua Tekoá, e, portanto, de poderem concretizar de maneira integral a sua existência, circunscrita pela materialização e subjetivação de seu Tekó, se expressa claramente nas entrelinhas do conceitual exposto acima, mas principalmente, na prática e na fala dirigida ao autor pelo cacique Karaí Ñee 're, o entendimento e a percepção deste povo sobre as limitações da composição cosmológica e cultural, que tal demarcação territorial assumirá, quando dinamicamente estiver submetida ao uso tradicional que os Mbyá the atribuírem. Assim, de modo bastante evidente, é perfeitamente claro para eles que a sua espacialidade, culturalmente compreendida, extrapola os limites físicos que a demarcação territorial da TI Tekoá Mirim lhes oferecerá, entretanto, necessidades elementares inclusive, fazem com que eles, também de modo consciente, passem a considerá-la, mobilizarem-se e articularem-se politicamente, para que este processo político - administrativo se efetue o mais breve possível.

Porém, de maneira também consciente, os Mbyá articulam novas ações políticas, para subverterem as limitações cosmológicas que a demarcação de sua tekoá lhes imputará quanto à concretização de seu Nhanderekó, isto é, concebem conscientemente, a rearticulação política de sua espacialidade, evidenciada pela tangência física das unidades: aldeias, quando legalmente já não podem contar com a existência de um único e vasto território Guarani. Esta proposição se evidencia na referida fala do cacique ao pesquisador, sobretudo, ao mostrar-lhe os limites de sua terra:

(...) lá, em cima da serra, vai acabar Tekoá Mirim. Mas, é onde começa a Tekoá Tenondé Porã. É a casa dos nossos parentes (...) vai dar para ir e voltar caminhando, Oguatá; sabe". (Karai Ñee're, entrevista, 15/07/2015, Tekoá Mirim).

Assim, constata-se de modo bastante claro, toda a vitalidade da percepção e entendimentos contemporâneos dos Mbyá que habitam o litoral paulista, acerca da territorialidade que concretiza e circunscreve suas aldeias. Portanto, para eles, suas Tekoá, são compreendidas como devendo existir, não como áreas isoladas e estanques - como quer decidir o Estado através dos procedimentos administrativos de demarcação de TIs - mas como um complexo geográfico, ambiental, social e econômico que compreende as aldeias do planalto, caminho de ligação e trilhas de coleta e caça às aldeias do litoral. Manter a integridade desse complexo é fundamental quando se observa que as áreas Guarani possuem exígua extensão territorial em seus limites decorrentes das demarcações realizadas pelas agências estatais responsáveis. 


\section{REFERÊNCIAS}

AZANHA, Gilberto e LADEIRA, Maria Inês. Os índios da serra do mar. São Paulo: Nova Stella, 1988. 178ps.

BRASIL. Decreto n ${ }^{0} 1.775$ de 08 de janeiro de 1996. Dispõe sobre o procedimento administrativo de demarcação das terras indígenas e dá outras providências. Disponível em: http://www.planalto.gov.br/ccivil_03/decreto/D1775.htm. Acesso em: 18 ago. 2018.

Portaria FUNAI n¹4 de 09 de janeiro de 1996. Estabelece regras sobre a elaboração do Relatório circunstanciado de identificação e delimitação de Terras Indígenas a que se refere o parágrafo $6^{\circ}$ do artigo $2^{\circ}$, do Decreto $n^{\circ} 1.775$, de 08 de janeiro de 1996. Disponível em: http://6ccr.pgr.mpf.mp.br/legislacao/ legislacao-docs/demarcacao/portaria_funai_14.pdf/view. Acesso em: 18 ago. 2018.

Projeto de Emenda Constitucional n²15 de 2000. Inclui dentre as competências exclusivas do Congresso Nacional a aprovação de demarcação das terras tradicionalmente ocupadas pelos índios e a ratificação das demarcações já homologadas; estabelecendo que os critérios e procedimentos de demarcação serão regulamentados por lei. Disponível em: http://www.camara.gov.br/proposicoesWeb/ fichadetramitacao?idProposicao=14562. Acesso em: 18 ago. 2018.

Lei n⿳0 9.985 de18 de julho de 2000. Regulamenta o art. 225, § 1ㅜㅜ, incisos I, II, III e VII da Constituição Federal, institui o Sistema Nacional de Unidades de Conservação da Natureza e dá outras providências. Disponível em: http://www. mma.gov.br/port/conama/legiabre.cfm?codlegi=322. Acesso em: 17 set. 2018.

Constituição da República Federativa do Brasil (1988). Brasília: Senado Federal, 2005. 283ps.

Decreto $n^{0}$ 6.040 de 07 de fevereiro de 2007. Institui a Política Nacional de Desenvolvimento Sustentável dos Povos e Comunidades Tradicionais. Disponível em: http://www.planalto.gov.br/ccivil_03/_ato2007-2010/2007/decreto/ d6040.htm. Acesso em: 17 set. 2018

Convenção $n^{\circ} 169$ sobre povos indígenas e tribais. Resolução referente 
à ação da OIT / Organização Internacional do Trabalho. Brasília: OIT, 2011.

CARNEIRO DA CUNHA, Manuela. Cultura com aspas e outros ensaios. São Paulo: Cosac Naify, 2014. 317ps.

CTI. Centro de Trabalho Indigenista. Mapa Guarani Digital. Disponível em: https://guarani.map.as/\#!/. Acesso em 6 jun. 2019.

COMISSÃO GUARANI YVYRUPA. A Comissão Guarani Yvy Rupa. Disponível em: http://videos.yvyrupa.org.br/a-cgy/. Acesso em: 17 set. 2018.

CLASTRES, Helene. A Terra Sem Mal. $2^{\text {a }}$ ed. São Paulo: Brasiliense, 1978. 217ps.

DIEGUES, Antônio Carlos. O mito moderno da natureza intocada. São Paulo: HUCITEC/NUPAUB - USP, 2000. 273ps.

FIGUEROA, Isabela e GARZON, Bivyani (Org.) Convenção 169 da OIT sobre povos indígenas e tribais: oportunidades e desafios para sua implementação no Brasil. São Paulo: Instituto Socioambiental, 2009. 376ps.

ISA. Instituto Socioambiental. Povos Indígenas no Brasil. Disponível em: https:// pib.socioambiental.org/pt/Povo:Guarani_Mbya. Acesso em 6 jun. 2019.

LADEIRA, Maria Inês. O Caminhar sob a Luz: território Mbyá à beira do oceano. São Paulo: UNESP/FAPESP, 2007. 201ps.

MARTINS, Fábio do Espírito Santo. Tekoá Mirim: terra indígena Mbyá Guarani. 2015. 127 f. Dissertação (mestrado) - Universidade Estadual Paulista Júlio de Mesquita Filho, Faculdade de Ciências e Letras (Campus de Araraquara), 2015. Disponível em: <http://hdl.handle.net/11449/127809>. Acesso em 17 set. 2018.

MONTEIRO, John e CARNEIRO DA CUNHA, Manuela (Org.) História dos Índios no Brasil. São Paulo: FAPESP/ SMC/ Cia. das Letras, 1992. 574ps.

NIMUENDAJU, Curt. As Lendas de Criação e Destruição do Mundo como Fundamentos da Religião dos Apapocúva Guarani. $3^{\mathrm{a}}$ ed. São Paulo: HUCITEC 
- EDUSP, 1987. 223ps.

OLIVEIRA FILHO, João Pacheco e GRUPIONI, Luís. (Org.) A Temática Indígena na Escola. Brasília: MEC/MARI/UNESCO, 1995. 407ps.

Introdução. (In):

Indigenismo e territorialização: poderes, rotinas e saberes coloniais no Brasil contemporâneo. Rio de Janeiro: Contracapa, 1998. ps. 204-259.

PISSOLATO, Elisabeth. A Duração da Pessoa: mobilidade, parentesco e xamanismo mbya (guarani). São Paulo: UNESP: ISA; Rio de Janeiro: NuTI, 2007. 275 ps.

SOUZA, Carlos de. Indigenismo e Territorialização. Horizontes Antropológicos. Ano 6, n'. 14, p. 311-316, nov. 2000. 